\title{
The Age-AST-D Dimer (AAD) Regression Model Predicts Severe COVID-19 Disease
}

\author{
Fátima Higuera-de-la-Tijera $\mathbb{D}^{\mathbb{D}},{ }^{1,2}$ Alfredo Servín-Caamaño $\mathbb{D}^{1},{ }^{1,3}$ Daniel Reyes-Herrera, ${ }^{1,3}$ \\ Argelia Flores-López $\mathbb{D}^{1,3}$ Enrique J. A. Robiou-Vivero ${ }^{1}{ }^{1,3}$ Felipe Martínez-Rivera ${ }^{1}{ }^{1,3}$ \\ Victor Galindo-Hernández $\mathbb{D},{ }^{1,3}$ Victor H. Rosales-Salyano $\mathbb{D},{ }^{1,3}$ \\ Catalina Casillas-Suárez ${ }^{\mathbb{D}},{ }^{1,4}$ Oscar Chapa-Azuela, ${ }^{1,5}$ Alfonso Chávez-Morales, ${ }^{1,6}$ \\ Billy Jiménez-Bobadilla, ${ }^{1,7}$ María L. Hernández-Medel, ${ }^{1,8}$ Benjamín Orozco-Zúñiga,,9 \\ Jed R. Zacarías-Ezzat, ${ }^{1,5}$ Santiago Camacho $\mathbb{D}^{1,2}$ and José L. Pérez-Hernández $\mathbb{D}^{1,2}$ \\ ${ }^{1}$ Multidisciplinary Team for the Attention and Care of Patients with COVID-19, Hospital General de México "Dr. Eduardo Liceaga", \\ Mexico City, Mexico \\ ${ }^{2}$ Gastroenterology and Hepatology Department, Hospital General de México "Dr. Eduardo Liceaga", Mexico City, Mexico \\ ${ }^{3}$ Internal Medicine Department, Hospital General de México "Dr. Eduardo Liceaga", Mexico City, Mexico \\ ${ }^{4}$ Pneumology Department, Hospital General de México "Dr. Eduardo Liceaga", Mexico City, Mexico \\ ${ }^{5}$ General Surgery Department, Hospital General de México "Dr. Eduardo Liceaga", Mexico City, Mexico \\ ${ }^{6}$ Intensive Care Unit, Hospital General de México "Dr. Eduardo Liceaga", Mexico City, Mexico \\ ${ }^{7}$ Colorectal Surgery Department, Hospital General de México "Dr. Eduardo Liceaga", Mexico City, Mexico \\ ${ }^{8}$ Infectious Disease Department, Hospital General de México "Dr. Eduardo Liceaga", Mexico City, Mexico \\ ${ }^{9}$ Ginecology Department, Hospital General de México "Dr. Eduardo Liceaga", Mexico City, Mexico
}

Correspondence should be addressed to Fátima Higuera-de-la-Tijera; fatimahiguera@yahoo.com.mx

Received 10 November 2020; Revised 8 January 2021; Accepted 12 March 2021; Published 26 March 2021

Academic Editor: Charat Thongprayoon

Copyright (c) 2021 Fátima Higuera-de-la-Tijera et al. This is an open access article distributed under the Creative Commons Attribution License, which permits unrestricted use, distribution, and reproduction in any medium, provided the original work is properly cited.

\footnotetext{
Aim. Coronavirus disease (COVID-19) ranges from mild clinical phenotypes to life-threatening conditions like severe acute respiratory syndrome (SARS). It has been suggested that early liver injury in these patients could be a risk factor for poor outcome. We aimed to identify early biochemical predictive factors related to severe disease development with intensive care requirements in patients with COVID-19. Methods. Data from COVID-19 patients were collected at admission time to our hospital. Differential biochemical factors were identified between seriously ill patients requiring intensive care unit (ICU) admission (ICU patients) versus stable patients without the need for ICU admission (non-ICU patients). Multiple linear regression was applied, then a predictive model of severity called Age-AST-D dimer (AAD) was constructed $(n=166)$ and validated $(n=170)$. Results. Derivation cohort: from 166 patients included, there were $27(16.3 \%)$ ICU patients that showed higher levels of liver injury markers $(P<0.01)$ compared with non-ICU patients: alanine aminotrasnferase (ALT) $225.4 \pm 341.2$ vs. $41.3 \pm 41.1$, aspartate aminotransferase (AST) $325.3 \pm 382.4$ vs. $52.8 \pm 47.1$, lactic dehydrogenase (LDH) $764.6 \pm 401.9$ vs. $461.0 \pm 185.6$, D-dimer (DD) $7765 \pm 9109$ vs. $1871 \pm 4146$, and age $58.6 \pm 12.7$ vs. $49.1 \pm 12.8$. With these finding, a model called Age-AST-DD (AAD), with a cut-point of $<2.75$ (sensitivity $=0.797$ and specificity $=0.391, c-$ statistic $=0.74 ; 95 \% \mathrm{IC}$ : $0.62-0.86, P<0.001)$, to predict the risk of need admission to ICU (OR =5.8; 95\% CI: 2.2-15.4, $P=0.001)$, was constructed. Validation cohort: in 170 different patients, the AAD model $<2.75(c-$ statistic $=0.80$ (95\% CI: $0.70-0.91, P<0.001)$ adequately predicted the risk $(\mathrm{OR}=8.8,95 \% \mathrm{CI}: 3.4-22.6, P<0.001)$ to be admitted in the ICU (27 patients, 15.95\%). Conclusions. The elevation of AST (a possible marker of early liver injury) along with DD and age efficiently predict early (at admission time) probability of ICU admission during the clinical course of COVID-19. The AAD model can improve the comprehensive management of COVID-19 patients, and it could be useful as a triage tool to early classify patients with a high risk of developing a severe clinical course of the disease.
} 


\section{Introduction}

The entire healthcare system's collapse is a serious public concern worldwide due to the pandemic caused by the severe acute respiratory syndrome coronavirus-2 (SARSCoV-2) infection. In the United States (US), the coronavirus disease (COVID-19) has given way to a nationwide public health catastrophe. For the first time in US history, a disaster declaration has been put in place for all 50 states and most US territories [1]. Until 26 September 2020, there were 32,626,165 confirmed SARS-CoV-2 infection cases worldwide and 990,134 deaths, according to the Center for Systems Science and Engineering (CSSE) at Johns Hopkins University (JHU) [2]. Mexico is one of the countries with a higher frequency of deaths due to the COVID-19 pandemic, with more than 70,000 deaths, a tally surpassed only by the US, Brazil, and India [3]. In this catastrophic scenario, results essential to understand the main factors related to a worse prognosis in the Mexican population.

COVID-19 ranges from mild clinical phenotypes to lifethreatening conditions like severe acute respiratory syndrome (SARS). Among COVID-19 patients, around 80\% are present with a mild illness whose symptoms usually disappear within two weeks. However, around $20 \%$ of the patients may develop severe symptoms requiring hospitalization. The mortality rate for this group of patients is around $13.4 \%$. Therefore, patient risk assessment, preferably in a quantitative, nonsubjective way, is essential for adequate patient management and medical resource allocation. The prognostic value of different variables is not yet fully understood [4].

Patients with COVID-19 often develop respiratory failure 8-14 days after symptom onset, with "silent hypoxemia" and a high respiratory rate $[5,6]$. Other authors have described examples of patients going from being physiologically normal to decompensating just a few hours later [7]. Therefore, further to oxygen saturation, recognizing poor prognosis factors that appear earlier during the disease is the key to prioritizing medical care for these high-risk patients, thus achieving effective triage in saturated healthcare systems. Our study is aimed at identifying the early biochemical factors determined at admission time, which were independent of pulmonary parameters, related to the disease course's progression, and the development of severe illness conditioning need to admission to the intensive care unit (ICU).

\section{Materials and Methods}

2.1. Study Design and Data Collection. This was an observational cohort study. First, we prospectively identified 166 patients with COVID-19 due to SARS-CoV-2 infection admitted to our hospital from March to May 2020. Demographic, clinical, and biochemical data at admission time were obtained from the medical records of these patients. Independent variables of interest were sex, age, glucose, urea, creatinine, lactic dehydrogenase (LDH), aspartate aminotransferase (AST), alanine aminotransferase (ALT), alkaline phosphatase (AP), gamma-glutamyl transferase (GGT), ferritin, D-dimer (DD), total platelet count, mean platelet volume (VPM), hemoglobin $(\mathrm{Hb})$, red cell distribution width (RDW), leukocytes, neutrophils, lymphocytes, brain natriuretic peptide (BNP), albumin, total proteins, direct bilirubin, indirect bilirubin, total cholesterol, triglycerides, sodium, potassium, chlorine, magnesium, phosphorus, calcium, fibrinogen, international normalized ratio (INR), C-reactive protein (CRP), creatine phosphokinase $(\mathrm{CPK})$, creatine phosphokinase-myocardial band (CPK-MB), troponin I, and myoglobin. Our primary outcome was to identify disease biomarkers in patients with severe disease needing ICU admission (ICU patients) and compare them with those who remained stable and needed only standard care support through supplementary oxygen by mask (non-ICU patients). There was not a search for specific predictors already reported in the literature because this sampling was time-depending. The intensive care medical staff evaluated all cases that need transfer to the ICU; SARS development was the most important reason to transfer patients to ICU. All patients transferred to ICU were intubated and supported with mechanical ventilation. The decision to transfer a patient to ICU and to initiate mechanical ventilation was always taken by the medical staff of the ICU. Patients were treated according to a previously established algorithm based on international standard care dictated by the Infectious Diseases Society of America (IDSA) [8].

2.2. Predictive Model Construction. Differential factors were identified between ICU patients versus non-ICU patients; these variables were then used to create a model to early predict (at admission time) whose patients were at risk to need transfer to the ICU at any time during the follow-up. The derivation and validation of the prediction model were designed according to the TRIPOD guidelines [9]. The Institutional Review Board approved the protocol.

2.3. Inclusion Criteria. Patients admitted to the hospitalization area because of confirmed COVID-19 due to SARS-CoV-2 infection by nasopharyngeal and oropharyngeal swab positive tests using real-time reverse transcription-polymerase chain reaction (RRT-PCR) taken at admission time.

2.4. Exclusion Criteria. Patients with incomplete information on their medical records. This was a per-protocol analysis, so the intention-to-treat analysis was not done.

2.5. Derivation Cohort. We included consecutive patients admitted from March to May 2020.

2.6. Validation Cohort. We included consecutive patients admitted from June to August 2020.

2.7. Statistical Analysis. Continuous variables were expressed as mean \pm standard deviation (SD). Categorical variables were expressed as frequencies and percents. Characteristics from ICU patients were compared with non-ICU patients. Differences between categorical variables were analyzed using the $\chi^{2}$ test or Fisher Exact test, whereas continuous variables were analyzed using two tails Student's $t$-test. A $P$ $\leq 0.01$ was considered significant.

To normalize the distribution of significant variables, we transformed it into their natural logarithm. The variables were ordered based on univariate significance by fitting a 


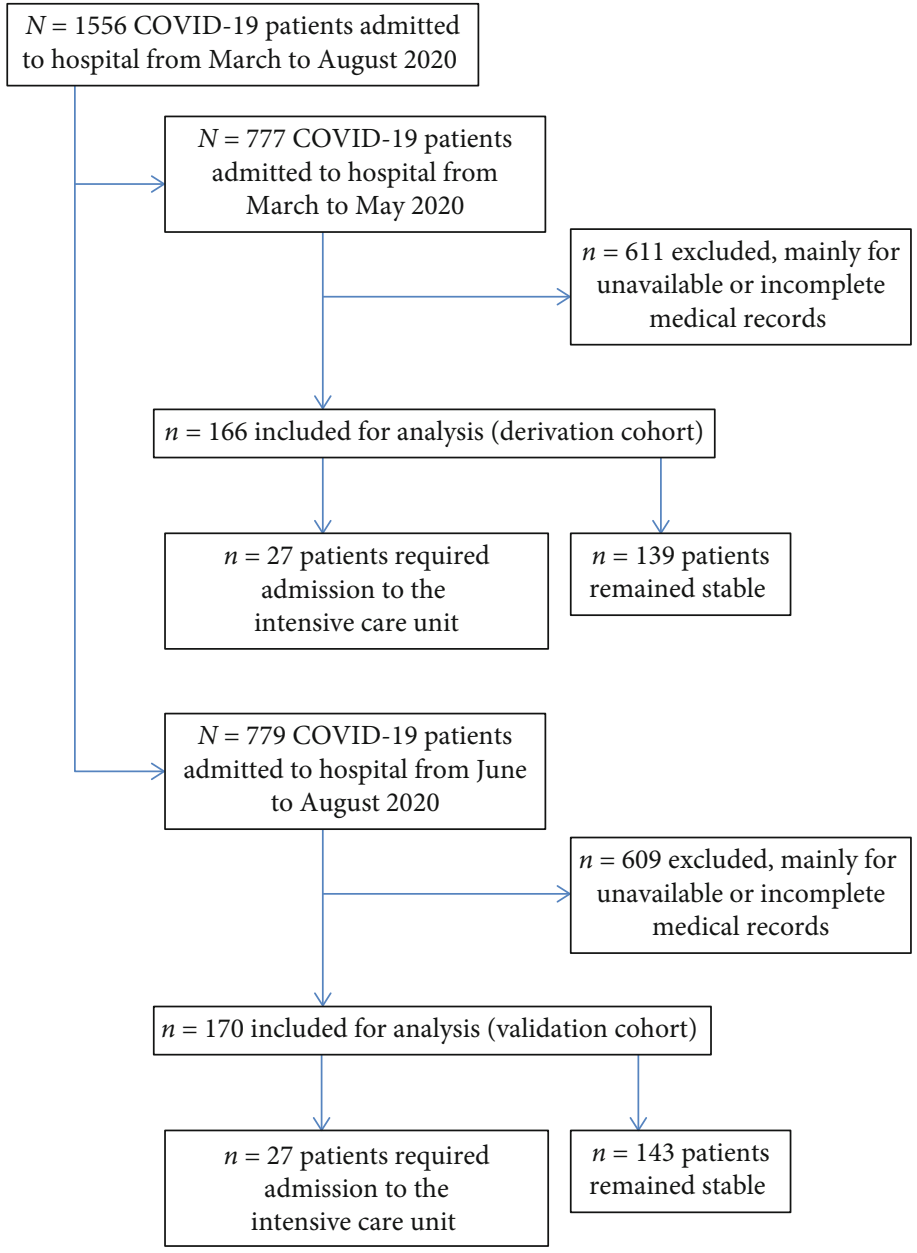

FIGURE 1: Enrolment of patients.

logistic regression model and added into the multivariate model using a forward selection procedure. Model selection was based on minimizing the Akaike information criterion and maximizing area underneath the receiver operator curve (AUROC) or concordance $c$-statistic, with priority given to the lowest Akaike information criterion. The final model named Age-AST-DD (AAD) was applied to both derivation and validation cohort, and AUROC analysis was performed to predict developing severe disease needing to be transferred to ICU. The model's diagnostic performance in derivation and validation cohorts was evaluated using sensitivity, 1-specificity, positive predictive value, negative predictive value, and diagnostic accuracy. All analyses were performed using IBM Corp. Released 2017. IBM SPSS Statistics for Windows, Version 25.0. Armonk, NY.

2.8. Sample Size. In a post hoc analysis (StatMate 2 for Windows), we found a power higher than $95 \%$ in the effect sizes of main variables (Age, AST, and DD), so we conclude that the sample size used to construct and then to validate de model was enough to get statistical validity.

\section{Results}

The enrolment of patients is summarized on the flowchart (see Figure 1).
3.1. Derivation Cohort. One hundred and sixty-six patients were included; from those, $114(68.7 \%)$ were men. The mean age was $50.6 \pm 13.3$ years old. A total of $27(16.3 \%)$ were ICU patients. In the comparative analysis between those ICU patients versus non-ICU patients, we found significant raises of ALT (225.4 \pm 341.2 vs. $41.3 \pm 41.1 ; P=0.003)$, AST $(325.3 \pm 382.4$ vs. $52.8 \pm 47.1 ; P=0.001), \mathrm{LDH}(764.6 \pm 401.9$ vs. $461.0 \pm$ 185.6; $P=0.001), \mathrm{DD}(7765 \pm 9109$ vs. $1871 \pm 4146 ; P=$ $0.003)$, and older age $(58.6 \pm 12.7$ vs. $49.1 \pm 12.8 ; P=0.001)$. See Table 1.

The results of the linear regression are shown in Table 2, where model 3 was the one that best explained the need for ICU admission, with these variables was constructed the model called AAD, where $[\mathrm{AAD}=3.896+\ln ($ age $) \mathrm{x}-0.218$ $+\ln (\mathrm{AST}) \mathrm{x}-0.185+\ln (\mathrm{DD}) \mathrm{x} 0.070]$, where a value $\leq 2.75$ had sensitivity $=0.797$ and 1 - specificity $=0.391, c-$ statistic $=0.74(95 \% \mathrm{CI}: 0.62-0.86 ; P<0.0001)$, to predict the risk of developing severe disease and need to ICU admission $(\mathrm{OR}=5.8,95 \% \mathrm{CI}: 2.2-15.4 ; P=0.001)$. See Figure 2 . The shrinkage factor for derivation sampling was 0.89 .

3.2. Validation Cohort. One hundred and seventy patients were included; from those, $116(68.2 \%)$ were men. The mean age was $50.9 \pm 12.8$ years old. A total of $27(15.9 \%)$ were ICU patients. The AADvalue $\leq 2.75$ in this cohort had 
TABLE 1: Comparison of admission characteristics between patients who developed SARS and required admission to ICU versus those with COVID-19 pneumonia without severity criteria.

\begin{tabular}{|c|c|c|c|}
\hline Variable & $\begin{array}{l}\text { Patients with SARS requiring } \\
\text { ICU admission }(n=27)\end{array}$ & $\begin{array}{l}\text { Patients with COVID-19 pneumonia without } \\
\text { severity criteria for ICU admission }(n=139)\end{array}$ & $P\left({ }^{*}<0.01\right)$ \\
\hline \multicolumn{4}{|c|}{ Demographic and clinical characteristics } \\
\hline Male/female gender, $n(\%)$ & $20 / 7(74.1 / 25.9)$ & $94 / 45(67.6 / 32.4)$ & 0.51 \\
\hline Age, years old & $58.6 \pm 12.7$ & $49.1 \pm 12.8$ & $0.001^{*}$ \\
\hline Tobacco consumption, $n(\%)$ & $7(25.9)$ & $26(18.7)$ & 0.43 \\
\hline Alcohol intake, $n(\%)$ & $3(11.1)$ & $13(9.3)$ & 0.73 \\
\hline Diabetes, $n(\%)$ & $8(29.6)$ & $48(34.5)$ & 0.82 \\
\hline Hypertension, $n(\%)$ & $5(18.5)$ & $45(32.4)$ & 0.25 \\
\hline \multicolumn{4}{|l|}{ Weight } \\
\hline Normal, $n(\%)$ & $11(40.7)$ & $45(32.4)$ & 0.53 \\
\hline Obesity, $n(\%)$ & $16(59.3)$ & $94(67.6)$ & \\
\hline COPD, $n(\%)$ & $6(22.2)$ & $8(5.7)$ & 0.01 \\
\hline Cardiovascular disease, $n(\%)$ & $3(11.1)$ & $10(7.2)$ & 0.45 \\
\hline Chronic liver disease, $n(\%)$ & $4(14.8)$ & $13(9.3)$ & 0.30 \\
\hline Chronic rheumatic disease, $n(\%)$ & $2(7.4)$ & $5(3.6)$ & 0.32 \\
\hline Dyslipidemia, $n(\%)$ & $9(33.3)$ & $17(12.2)$ & 0.02 \\
\hline Chronic kidney disease, $n(\%)$ & $3(11.1)$ & $6(22.2)$ & 0.12 \\
\hline Cancer, $n(\%)$ & $1(3.7)$ & $14(10.1)$ & 0.46 \\
\hline AIDS, $n(\%)$ & $1(3.7)$ & $1(0.7)$ & 0.30 \\
\hline $\begin{array}{l}\text { Use of immunosuppressive medication } \\
\text { different than steroids, } n(\%)\end{array}$ & $2(7.4)$ & $6(4.3)$ & 0.62 \\
\hline \multicolumn{4}{|l|}{ Chronic use of steroids } \\
\hline No, $n(\%)$ & $27(100)$ & $133(95.7)$ & 0.55 \\
\hline Low dose, $n(\%)$ & $0(0)$ & $4(2.9)$ & \\
\hline High dose, $n(\%)$ & $0(0)$ & $2(1.4)$ & \\
\hline \multicolumn{4}{|l|}{ Liver function tests } \\
\hline Albumin, g/dL & $3.27 \pm 0.52$ & $3.48 \pm 0.50$ & 0.09 \\
\hline Alanine aminotransferase, UI/L & $225.4 \pm 341.2$ & $41.3 \pm 41.1$ & $0.003^{*}$ \\
\hline Aspartate aminotransferase, UI/L & $325.3 \pm 382.4$ & $52.8 \pm 47.1$ & $0.001^{*}$ \\
\hline Alkaline phosphatase, UI/L & $109.1 \pm 74.8$ & $96.8 \pm 54.4$ & 0.39 \\
\hline Gamma Glutamyl Transferase, UI/L & $205.6 \pm 360.4$ & $125.4 \pm 163.3$ & 0.35 \\
\hline Direct bilirubin, $\mathrm{mg} / \mathrm{dL}$ & $0.8 \pm 1.7$ & $0.3 \pm 0.3$ & 0.23 \\
\hline Indirect bilirubin, mg/dL & $0.8 \pm 1.1$ & $0.5 \pm 0.3$ & 0.31 \\
\hline \multicolumn{4}{|l|}{ Biochemical serum analysis } \\
\hline Glucose, $\mathrm{mg} / \mathrm{dL}$ & $168.2 \pm 95.0$ & $149.8 \pm 97.8$ & 0.54 \\
\hline Urea, mg/dL & $54.7 \pm 37.0$ & $42.1 \pm 37.7$ & 0.14 \\
\hline Creatinine, $\mathrm{mg} / \mathrm{dL}$ & $1.1 \pm 0.7$ & $0.9 \pm 0.7$ & 0.29 \\
\hline Cholesterol, mg/dL & $102.9 \pm 33.8$ & $123.0 \pm 27.0$ & 0.03 \\
\hline Triglycerides, mg/dL & $142.4 \pm 45.8$ & $145.7 \pm 49.4$ & 0.83 \\
\hline Total proteins, g/dL & $6.5 \pm 0.7$ & $6.3 \pm 1.0$ & 0.60 \\
\hline Lactic dehydrogenase, UI/L & $764.6 \pm 401.9$ & $461.0 \pm 185.6$ & $0.001^{*}$ \\
\hline \multicolumn{4}{|l|}{ Serum electrolytes } \\
\hline Sodium, mmol/L & $128.8 \pm \pm 26.8$ & $135.8 \pm 3.5$ & 0.38 \\
\hline Potassium, mmol/L & $4.2 \pm 0.4$ & $4.0 \pm 0.5$ & 0.19 \\
\hline Chlorine, $\mathrm{mmol} / \mathrm{L}$ & $102.2 \pm 5.04$ & $100.6 \pm 4.35$ & 0.25 \\
\hline Calcium, mg/dL & $7.8 \pm 0.47$ & $8.0 \pm 0.44$ & 0.77 \\
\hline
\end{tabular}


TABle 1: Continued.

\begin{tabular}{|c|c|c|c|}
\hline Variable & $\begin{array}{l}\text { Patients with SARS requiring } \\
\text { ICU admission }(n=27)\end{array}$ & $\begin{array}{l}\text { Patients with COVID-19 pneumonia without } \\
\text { severity criteria for ICU admission }(n=139)\end{array}$ & $P\left({ }^{*}<0.01\right)$ \\
\hline Phosphorus, mg/dL & $3.2 \pm 1.0$ & $3.1 \pm 0.8$ & 0.75 \\
\hline Magnesium, mg/dL & $2.3 \pm 0.3$ & $2.2 \pm 0.4$ & 0.27 \\
\hline \multicolumn{4}{|l|}{ Hematic cytometry } \\
\hline Leukocytes, cells $/ \mathrm{mm}^{3}$ & $10.3 \pm 5.1$ & $8.7 \pm 4.5$ & 0.23 \\
\hline Neutrophils, cells $/ \mathrm{mm}^{3}$ & $8.9 \pm 4.6$ & $7.1 \pm 4.2$ & 0.09 \\
\hline Lymphocytes, cells $/ \mathrm{mm}^{3}$ & $1.0 \pm 0.4$ & $1.0 \pm 0.6$ & 0.99 \\
\hline Hemoglobin, g/dL & $14.7 \pm 1.7$ & $14.5 \pm 2.3$ & 0.82 \\
\hline Red cells wide distribution & $14.8 \pm 1.4$ & $14.2 \pm 1.4$ & 0.15 \\
\hline Platelets, cells/mL & $219.7 \pm 73.1$ & $226.4 \pm 86.2$ & 0.77 \\
\hline Mean platelet volume, $\mathrm{fL}$ & $8.9 \pm 0.9$ & $8.4 \pm 0.9$ & 0.11 \\
\hline \multicolumn{4}{|c|}{ Coagulation tests and inflammatory profile } \\
\hline International normalized ratio & $1.1 \pm 0.2$ & $1.0 \pm 0.3$ & 0.63 \\
\hline Fibrinogen, mg/dL & $640.7 \pm 207.5$ & $608.6 \pm 168.9$ & 0.54 \\
\hline D-dimer, ng/mL & $7765 \pm 9109$ & $1871 \pm 4146$ & $0.003^{*}$ \\
\hline Reactive $\mathrm{C}$ protein, $\mathrm{mg} / \mathrm{L}$ & $210.3 \pm 157.4$ & $142.7 \pm 121.2$ & 0.17 \\
\hline Ferritin, ng/mL & $782 \pm 518$ & $786 \pm 1011$ & 0.98 \\
\hline \multicolumn{4}{|l|}{ Muscle enzymes } \\
\hline Creatine phosphokinase, UI/L & $169 \pm 188$ & $300 \pm 462$ & 0.36 \\
\hline Myoglobin, ng/mL & $151 \pm 151$ & $110 \pm 192$ & 0.47 \\
\hline \multicolumn{4}{|l|}{ Cardiac enzymes and peptides } \\
\hline Troponin I, ng/L & $49.4 \pm 136.7$ & $26.1 \pm 96.3$ & 0.45 \\
\hline CPK-MB, ng/dL & $34 \pm 42$ & $25 \pm 17$ & 0.29 \\
\hline Brain natriuretic peptide, $\mathrm{pg} / \mathrm{mL}$ & $56.9 \pm 80.5$ & $136.1 \pm 342.2$ & 0.49 \\
\hline
\end{tabular}

AIDS: acquired immunodeficiency syndrome; COPD: chronic obstructive pulmonary disease; ICU: intensive care unit; SARS: severe acute respiratory distress syndrome.

TABLE 2: Multivariate linear regression models predictive of severe disease in patients with COVID-19 and requirement for ICU admission.

\begin{tabular}{|c|c|c|c|c|c|c|c|c|c|}
\hline \multirow{2}{*}{\multicolumn{2}{|c|}{ Model }} & \multicolumn{2}{|c|}{$\begin{array}{l}\text { Nonstandardized } \\
\text { coefficients }\end{array}$} & \multirow{2}{*}{$\begin{array}{c}\text { Standardized coefficients } \\
\text { Beta } \\
\end{array}$} & \multirow[t]{2}{*}{$P$} & \multicolumn{2}{|c|}{$95 \%$ confidence interval for B } & \multicolumn{2}{|c|}{$\begin{array}{l}\text { Colinearity } \\
\text { statistics }\end{array}$} \\
\hline & & $B$ & Error deviation & & & Inferior limit & Superior limit & Tolerance & VIF \\
\hline \multirow{3}{*}{1} & $\mathrm{C}$ & 2.721 & 0.131 & & $<0.001$ & 2.462 & 2.980 & & \\
\hline & AST & -0.229 & 0.033 & -0.512 & $<0.001$ & -0.293 & -0.164 & 1.000 & 1.000 \\
\hline & $\mathrm{C}$ & 3.161 & 0.198 & & $<0.001$ & 2.770 & 3.551 & & \\
\hline \multirow[t]{3}{*}{2} & AST & -0.194 & 0.034 & -0.435 & $<0.001$ & -0.261 & -0.127 & 0.878 & 1.139 \\
\hline & $\mathrm{DD}$ & -0.081 & 0.028 & -0.221 & 0.01 & -0.135 & -0.026 & 0.878 & 1.139 \\
\hline & $\mathrm{C}$ & 3.896 & 0.414 & & $<0.001$ & 3.077 & 4.714 & & \\
\hline \multirow{3}{*}{3} & AST & -0.185 & 0.034 & -0.413 & $<0.001$ & -0.252 & -0.118 & 0.860 & 1.163 \\
\hline & $\mathrm{DD}$ & -0.070 & 0.028 & -0.190 & 0.01 & -0.125 & -0.014 & 0.844 & 1.185 \\
\hline & Age & -0.218 & 0.108 & -0.148 & 1.05 & -0.433 & -0.004 & 0.915 & 1.093 \\
\hline
\end{tabular}

AST: aspartate aminotransferase; C: constant; DD: D-dimer; VIF: variance inflation factors. Resume of the model: (1) $R=0.512, r^{2}=0.262, r^{2}$ adjusted $=0.256$, standard error $=0.331$. (2) $R=0.552, r^{2}=0.305, r^{2}$ adjusted $=0.294$, standard error $=0.322$. (3) $R=0.570, r^{2}=0.325, r^{2}$ adjusted $=0.310$, standard error $=$ 0.318 . Durbin - Watson $=1.53$. 


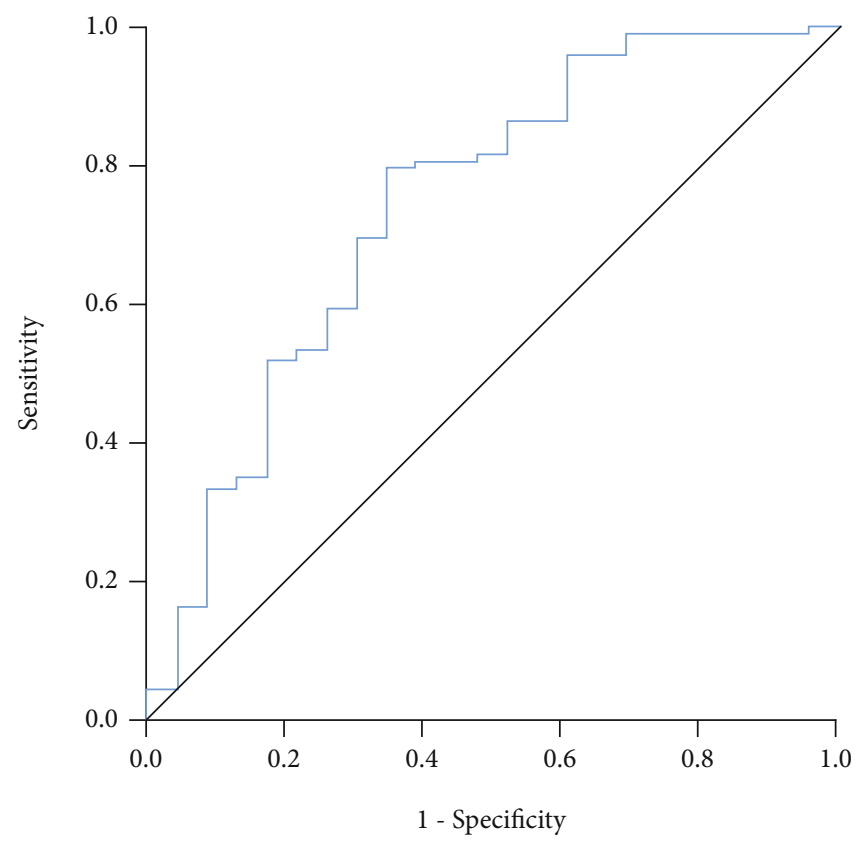

FIgURE 2: Derivation cohort $(n=166)$ : AAD model to predict ICU admission. $c$ - statistic $=0.74$ (95\% CI: $0.62-0.86 ; P<0.0001)$.

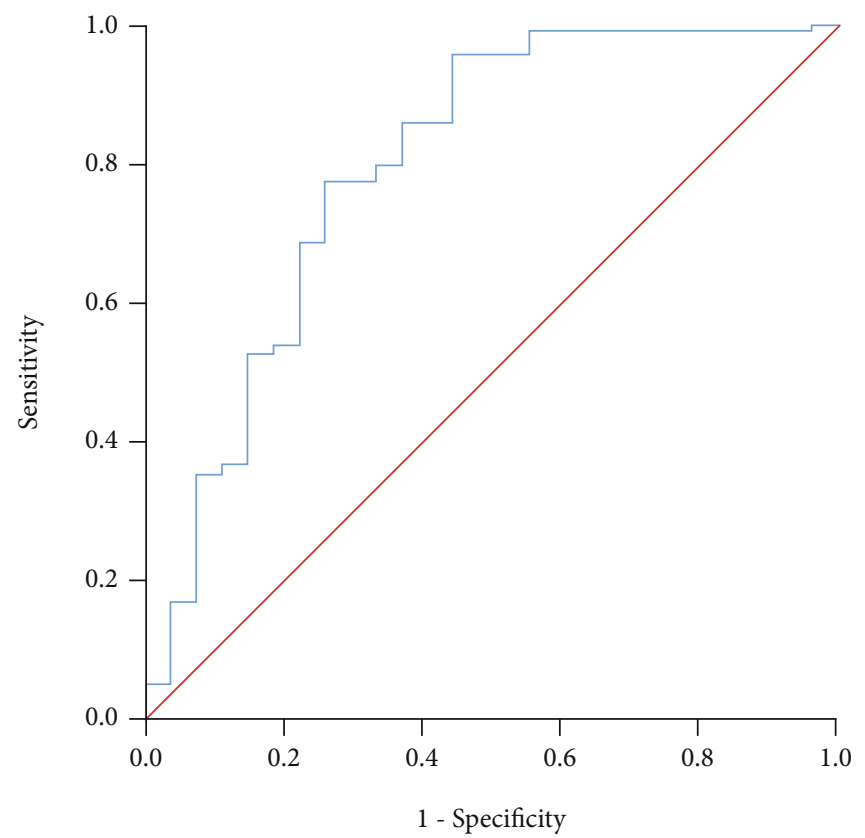

FIgURe 3: Validation cohort $(n=170)$ : AAD model to predict ICU admission. $c$ - statistic $=0.80$ (95\% CI: $0.70-0.91 ; P<0.0001)$.

sensitivity $=0.77$ and $1-$ specificity $=0.26, c-$ statistic $=0.80$ (95\% CI: $0.70-0.91 ; P<0.0001$ ), to predict the risk of requiring ICU admission (OR = 8.8, 95\% CI: 3.4-22.6; $P<0.0001)$. See Figure 3 . The shrinkage factor for validation sampling was 0.88 .

\section{Discussion}

In this study, we develop a regression model using early biomarkers to predict the severity of COVID-19, assessing the need for admission to ICU. Cytokine storm, SARS, and systemic inflammation-related pathology characterize severe
COVID-19 [10]. Liver injury is common and is associated with disease severity in patients infected by the other two significant coronavirus-SARS-CoV and the Middle East respiratory syndrome coronavirus [11-14]. Between 14.8\% and $53 \%$ of COVID-19 patients had hepatocellular liver injury demonstrated by higher ALT or AST and slightly high bilirubin levels [15]. Moreover, liver injury frequency is higher in severe COVID-19 [16-19] and increases the mortality as high as 58 to $78 \%[20,21]$.

Our study found that early liver injury, assessed by elevated aminotransferases, particularly AST, is a factor 
related to the worst progression in COVID-19 patients who require entering to ICU. Huang et al. [19] showed that AST elevation was observed in $8(62 \%)$ of 13 patients in the ICU compared with 7 (25\%) of 28 patients who did not require ICU admission. Wang et al. [22] also found that patients admitted to ICU had significantly higher ALT (35 vs. 23, $P=0.007$ ) and AST (52 vs. $29, P<0.001$ ) levels. Our study results confirm the finding that liver injury is more prevalent in severe cases of COVID-19.

According to several studies, high values of CRP, ferritin, $\mathrm{DD}$, procalcitonin, $\mathrm{LDH}$, prothrombin time, activated partial thromboplastin time, amyloid serum protein $\mathrm{A}, \mathrm{CPK}$, GGT, urea, and creatinine are risk factors for severe disease, thromboembolic complications, myocardial damage, and worse prognosis [23-26]. In addition to aminotransferases, in our study, many of these factors were higher in ICU patients than in non-ICU patients, but the most important associated with severe disease were LDH and DD. The most severely ill patients usually present with coagulopathy, and disseminated intravascular coagulation- (DIC-) like massive intravascular clot formation is frequently seen in this group of patients $[27,28]$. Therefore, as we found in our AAD predictive model, coagulation tests, specifically DD [29], may be considered useful to discriminate severe cases of COVID-19. Changes in hemostatic biomarkers represented by an increase in DD and fibrin/fibrinogen degradation products indicate the essence of coagulopathy is massive fibrin formation [28].

Liver injury in patients with COVID-19 might be due to viral infection in liver cells or due to other causes such as drug-induced liver injury (DILI) and systemic inflammation induced by cytokine storm or pneumonia-associated hypoxia [30]. A significant limitation of our study is that we were not able to correlate the biochemical findings at admission with liver biopsy in these patients; therefore, we are unable to determine if the serum alterations observed in liver function tests, particularly aminotransferases, are due to direct viral infection of the liver parenchyma. Another significant limitation is that the received therapy in these patients was heterogeneous regarding the date of starting, type of medication, and the dose of the medications, then we do not collect data from the received therapy of these patients; therefore, we cannot perform a subanalysis to try to identify potential DILI contributing to liver injury.

\section{Conclusions}

The elevation of AST (a possible marker of early liver injury) along with D-dimer and age efficiently early predict (at admission time) the probability of needing ICU admission during the clinical course of COVID-19. Our findings support using the AAD model to accurately determine those patients who would need to be transferred to ICU because of a severe clinical course of their disease. The AAD model can improve the comprehensive management of COVID-19 patients, and it could be useful as a triage tool to early classify patients with a high risk of developing a severe clinical course of the disease.

\section{Data Availability}

The datasets generated and analyzed in this study are not publicly available because of respect to and protect patient privacy but are available from the corresponding authors on reasonable request.

\section{Disclosure}

Preliminary results of this work were presented as an abstract as cartel at the Annual Meeting of the Mexican Association of Hepatology (AMH)-XV Congreso Nacional de Hepatología, Online modality held on July 23-25, 2020.

\section{Conflicts of Interest}

The authors have no conflicts of interest to disclose.

\section{Authors' Contributions}

Fátima Higuera-de-la-Tijera designed the overall concept of the study, performed the statistical analysis, and wrote the final manuscript; Alfredo Servín-Caamaño designed the overall concept of the study and supervised the writing of the manuscript; Daniel Reyes-Herrera, Argelia Flores-López, Enrique J.A. Robiou-Vivero, Felipe Martínez-Rivera, Victor Galindo-Hernández, Victor H. Rosales-Salyano, Catalina Casillas-Suárez, Oscar Chapa-Azuela, Alfonso ChávezMorales, Billy Jiménez-Bobadilla, María L. Hernández-Medel, Benjamín Orozco-Zúñiga, and Jed R. Zacarías-Ezzat collected the data of all patients; Santiago Camacho provided support to perform the statistical analysis, tables, and figures; José L. Pérez-Hernández helped to design the mathematical model and contributed to edit the final manuscript.

\section{Acknowledgments}

Luis Servín-Abad, MD, Gastroenterologist at Saint Cloud Hospital, Centracare, St. Cloud, Minnesota, 56303, United States of America contributed to edit the English language version of this manuscript.

\section{References}

[1] The Lancet, "COVID-19 in the USA: a question of time," Lancet, vol. 395, no. 10232, p. 1229, 2020.

[2] Johns Hopkins Resource Center, COVID-19 map, Johns Hopkins Coronavirus Resource Center, 2020.

[3] D. Agren, "Understanding Mexican health worker COVID-19 deaths," Lancet, vol. 396, no. 10254, p. 807, 2020.

[4] G. Wu, P. Yang, Y. Xie et al., "Development of a clinical decision support system for severity risk prediction and triage of COVID-19 patients at hospital admission: an international multicentre study," European Respiratory Journal, vol. 56, no. $2,2020$.

[5] Y. Li and S.-Y. Xiao, "Hepatic involvement in COVID-19 patients: pathology, pathogenesis, and clinical implications," Journal of Medical Virology, vol. 92, no. 9, pp. 1491-1494, 2020. 
[6] F. Zhou, T. Yu, R. Du et al., "Clinical course and risk factors for mortality of adult inpatients with COVID-19 in Wuhan, China: a retrospective cohort study," Lancet, vol. 395, no. 10229 , pp. $1054-1062$.

[7] W. Ottestad, M. Seim, and J. O. Mæhlen, "Covid-19 med stille hypoksemi," Tidsskr den Nor Laegeforening, vol. 140, 2020.

[8] Infectious Diseases Society of America, Infectious Diseases Society of America guidelines on the treatment and management of patients with COVID-19 https://www.idsociety.org/ practice-guideline/covid-19-guideline-treatment-andmanagement/.

[9] G. S. Collins, J. B. Reitsma, D. G. Altman, and K. G. M. Moons, "Transparent reporting of a multivariable prediction model for individual prognosis or diagnosis (TRIPOD): the TRIPOD statement," Annals of Internal Medicine, vol. 162, no. 1, pp. 55-63, 2015.

[10] B. D. Pence, "Severe COVID-19 and aging: are monocytes the key?," Gero Science, vol. 42, no. 4, pp. 1051-1061, 2020.

[11] J. Li and J.-G. Fan, "Characteristics and mechanism of liver injury in 2019 coronavirus disease," Journal of Clinical and Translational Hepatology, vol. 8, no. 1, pp. 1-5, 2020.

[12] Y.-J. Tan, B. C. Fielding, P.-Y. Goh et al., "Overexpression of $7 \mathrm{a}$, a protein specifically encoded by the severe acute respiratory syndrome coronavirus, induces apoptosis via a caspasedependent pathway," Journal of Virology, vol. 78, no. 24, pp. 14043-14047, 2004.

[13] D. L. Ng, F. Al Hosani, M. K. Keating et al., "Clinicopathologic, immunohistochemical, and ultrastructural findings of a fatal case of middle east respiratory syndrome coronavirus infection in the United Arab Emirates, April 2014," The American Journal of Pathology, vol. 186, no. 3, pp. 652-658, 2016.

[14] K. O. Alsaad, A. H. Hajeer, M. Al Balwi et al., "Histopathology of Middle East respiratory syndrome coronovirus (MERS$\mathrm{CoV}$ ) infection - clinicopathological and ultrastructural study," Histopathology, vol. 72, no. 3, pp. 516-524, 2018.

[15] L. Xu, J. Liu, M. Lu, D. Yang, and X. Zheng, "Liver injury during highly pathogenic human coronavirus infections," Liver International, vol. 40, no. 5, pp. 998-1004, 2020.

[16] Q. Cai, D. Huang, P. Ou et al., "COVID-19 in a designated infectious diseases hospital outside Hubei Province, China," Allergy, vol. 75, no. 7, pp. 1742-1752, 2020.

[17] Z. Fan, L. Chen, J. Li et al., "Clinical features of COVID-19related liver functional abnormality," Clinical Gastroenterology and Hepatology, vol. 18, no. 7, pp. 1561-1566, 2020.

[18] W. Guan, Z. Ni, Y. Hu et al., "Clinical characteristics of coronavirus disease 2019 in China," The New England Journal of Medicine, vol. 382, no. 18, pp. 1708-1720, 2020.

[19] C. Huang, Y. Wang, X. Li et al., "Clinical features of patients infected with 2019 novel coronavirus in Wuhan, China," Lancet, vol. 395, no. 10223, pp. 497-506, 2020.

[20] B. Zhang, X. Zhou, Y. Qiu et al., "Clinical characteristics of 82 cases of death from COVID-19," PLoS One, vol. 15, no. 7, p. e0235458, 2020.

[21] C. Ying Huang, R. Yang, Y. Xu, and P. Gong, Clinical characteristics of 36 non-survivors with COVID-19 in Wuhan, China, 2020.

[22] D. Wang, R. Hu, C. Hu et al., "Clinical characteristics of 138 hospitalized patients with 2019 novel coronavirus-infected pneumonia in Wuhan, China," JAMA, vol. 323, no. 11, pp. 1061-1069, 2020.
[23] N. Vabret, G. J. Britton, C. Gruber et al., "Immunology of COVID-19: current state of the science," Immunity, vol. 52, no. 6, pp. 910-941, 2020.

[24] A. K. Azkur, M. Akdis, D. Azkur et al., "Immune response to SARS-CoV-2 and mechanisms of immunopathological changes in COVID-19," Allergy, vol. 75, no. 7, pp. 1564$1581,2020$.

[25] M. Kermali, R. K. Khalsa, K. Pillai, Z. Ismail, and A. Harky, "The role of biomarkers in diagnosis of COVID-19 - a systematic review," Life Sciences, vol. 254, p. 117788, 2020.

[26] G. Chen, D. Wu, W. Guo et al., "Clinical and immunological features of severe and moderate coronavirus disease 2019," The Journal of Clinical Investigation, vol. 130, no. 5, pp. 2620-2629, 2020.

[27] T. Iba, J. H. Levy, M. Levi, and J. Thachil, "Coagulopathy in COVID-19," Journal of Thrombosis and Haemostasis, vol. 18, no. 9, pp. 2103-2109, 2020.

[28] J. M. Connors and J. H. Levy, "COVID-19 and its implications for thrombosis and anticoagulation," Blood, vol. 135, no. 23, pp. 2033-2040, 2020.

[29] W. Miesbach and M. Makris, "COVID-19: coagulopathy, risk of thrombosis, and the rationale for anticoagulation," Clinical and Applied Thrombosis/Hemostasis, vol. 26, p. $107602962093814,2020$.

[30] C. Zhang, L. Shi, and F.-S. Wang, "Liver injury in COVID-19: management and challenges," The Lancet Gastroenterology \& Hepatology, vol. 5, no. 5, pp. 428-430, 2020. 